2016-10

Head injury in the elderly - what are the outcomes of neurosurgical care?

Whitehouse, KJ

http://hdl.handle.net/10026.1/5216

10.1016/j.wneu.2016.07.057

World neurosurgery

Elsevier BV

All content in PEARL is protected by copyright law. Author manuscripts are made available in accordance with publisher policies. Please cite only the published version using the details provided on the item record or document. In the absence of an open licence (e.g. Creative Commons), permissions for further reuse of content should be sought from the publisher or author. 


\section{Head injury in the elderly - what are the outcomes of neurosurgical care?}

Corresponding author: Kathrin Joanna Whitehouse BSc ${ }^{a, b}$ kathrin.whitehouse@nhs.net

Deva Sanjeeva Jeyaretna $\mathrm{MD}^{\mathrm{C}}$ sanjeeva.jeyaretna@ouh.nhs.uk

Doyo Gragn Enki PhDd doyo.enki@plymouth.ac.uk

Peter C Whitfield PhDa peter.whitfield@nhs.net

a South West Neurosurgery Centre, Derriford Hospital, Derriford Road, Plymouth. PL6 8DH.

${ }^{\mathrm{b}}$ (Present address) Department of Neurosurgery, Southmead Hospital, Southmead Road, Westbury-on-Trym

${ }^{c}$ Department of Neurosurgery and Nuffield Department of Clinical Neurosciences, University of Oxford, John Radcliffe hospital, Headley Way, Oxford

d Medical Statistics Group, Plymouth University Peninsula Schools of Medicine and Dentistry, Plymouth Science Park, Derriford, Plymouth. PL6 8BX. 


\section{Abstract}

\section{Background}

The population of those presenting with head trauma is ageing. Studies show varying outcomes for this subgroup.

\section{Methods}

The notes and imaging were reviewed of all patients aged $\geq 75$ years with head injury admitted to a regional neurosurgical unit from $01 / 01 / 2007$ to $31 / 12 / 2010$. Mortality data up to $31 / 12 / 2012$ was attained from national databases. Outcomes included death as an inpatient, by 30 days and 1 year post-discharge; GOS; discharge GCS; recurrence; readmission; reoperation; and complication.

\section{Results}

263 patients were admitted, 26 with acute subdural haematoma (ASDH); 175 with chronic subdural haematoma (CSDH); and 46 with mixed subdural collections (ACSDH). Sixteen patients predominantly had other injuries, such as contusions and fractures.

Those with ASDHs had a significantly lower survival rate than those with CSDH or ACSDH. The odds of inpatient death for ASDH patients was 15.38 (vs CSDHs). For all SDHs, low ASA predicted death as an inpatient and at 30 days.

Death at one year was predicted by moderate/severe admission GCS ( $p=0.028)$, long anaesthetic $(p=0.002)$, and the presence of bilateral SDH $(p=0.002)$.

Unsatisfactory GOS (1-3) was predicted by age over 85y $(p=0.029)$; larger depth of subdural $(p<0.001)$; and presence of complication $(p=0.003)$. Recurrence and reoperation were only predicted by bilateral site of SDH. Those aged over 90 with presentation GCS under 10 all had poor outcomes.

\section{Conclusions}

Most elderly patients admitted under neurosurgery after head injury have SDHs. Our results are better than many previously reported, however the rate of death for those with ASDH is still high. 


\section{Introduction}

The population of the world is ageing, with estimates that there will be almost 2 billion people over the age of 60 years by $2050,{ }^{1}$ and the consequences of this are being felt in healthcare systems. Two-thirds of UK acute hospital admissions are over the age of $65,,^{2}$ and serious head injury among patients 70 years and over is associated with high mortality. ${ }^{3}$ Subdural haematomas are four times larger in the elderly and produce twice the mass effect, when compared to younger patients. ${ }^{4}$ Indeed, in their series, Ritchie et al (2000) found that there were no satisfactory outcomes for head injury patients over the age of 80 with an initial GCS under 13, and that all those with an initial GCS under 11 were either dead, vegetative or required full nursing care upon discharge. ${ }^{5}$

We aimed to describe the characteristics and outcomes of elderly patients admitted to our neurosurgical unit. Factors related to complications and mortality are also analysed, in order to inform future decision-making. The term "elderly" is variably defined, but for the purposes of this study, a cut-off age of 75 years was used.

\section{Material and methods}

A retrospective review was undertaken of the medical records and imaging of all patients aged 75 and over, admitted for at least one night to the South West Neurosurgery Centre, UK, from January $1^{\text {st }} 2007$ to December $31^{\text {st }} 2010$. A minimum of 2 years' mortality data, up to $31^{\text {st }}$ December 2012, was extracted from the Demographics Batch Service and the national NHS Spine database. A description of the methods used, and data collected for the entire cohort is described elsewhere. ${ }^{6}$ Patients were included in this study if they were admitted with a head injury, as determined by history, physical examination or radiological examination. Diagnoses were categorised into the main finding on preliminary imaging, but where the imaging could not be seen, the diagnosis used by the admitting neurosurgeon in the medical records was used. Scans were reviewed and measurements made by the primary author $(\mathrm{KW})$. Independent variables included gender, age, preliminary diagnosis, admission Glasgow Coma Score (GCS, categorised as severe, moderate or mild), 
length of anaesthetic for those who underwent operation, type of operation, American Society of Anesthesiologists score (ASA, categorised into groups 1 - 3 and $4-5$, due to low numbers of the lower grades), smoking status, side of spaceoccupying lesion, anticoagulation, maximum depth of haematoma (measured as the maximum depth on axial CT), and midline shift (measured as the maximum distance of the falx cerebri from a line joining the internal occipital protruberance and the frontal crest).

Outcomes included discharge GCS (categorised as "mild head injury" at GCS 13-15, "moderate" 9-12 and "severe" 3-8), Glasgow Outcome Score (GOS, with poor/unsatisfactory outcome classified as GOS 1, 2 or 3; and satisfactory as 4 or 5), death as inpatient, death by 30 days, death by one year post-admission, recurrence, readmission, reoperation and complication. For normally-distributed data, mean and standard deviation were used for descriptive purposes, for data that was not normally-distributed, medians and ranges were used. Statistical significance was set at 5\%. Statistical analysis was performed using SPSS Statistics 22.

To compare characteristics, chi-squared tests were used. In order to find which independent variables predicted outcomes, multiple logistic regression was used.

\section{Results}

\section{Patient characteristics}

A total of 886 elderly patients were admitted during the four year study period, of which 877 sets of medical records were available to review. The characteristics of the whole cohort are described elsewhere. ${ }^{6} 263$ patients had sustained a head injury. Of these, 255 scans could be reviewed and diagnoses confirmed; for the remaining eight patients, the diagnoses documented in the notes were relied upon. The median age at admission was 82 years (range 75 - 97 years, SD 5.16). 81 patients were female, 182 were male.

Figure 1 shows the ages of all patients included in this study. 


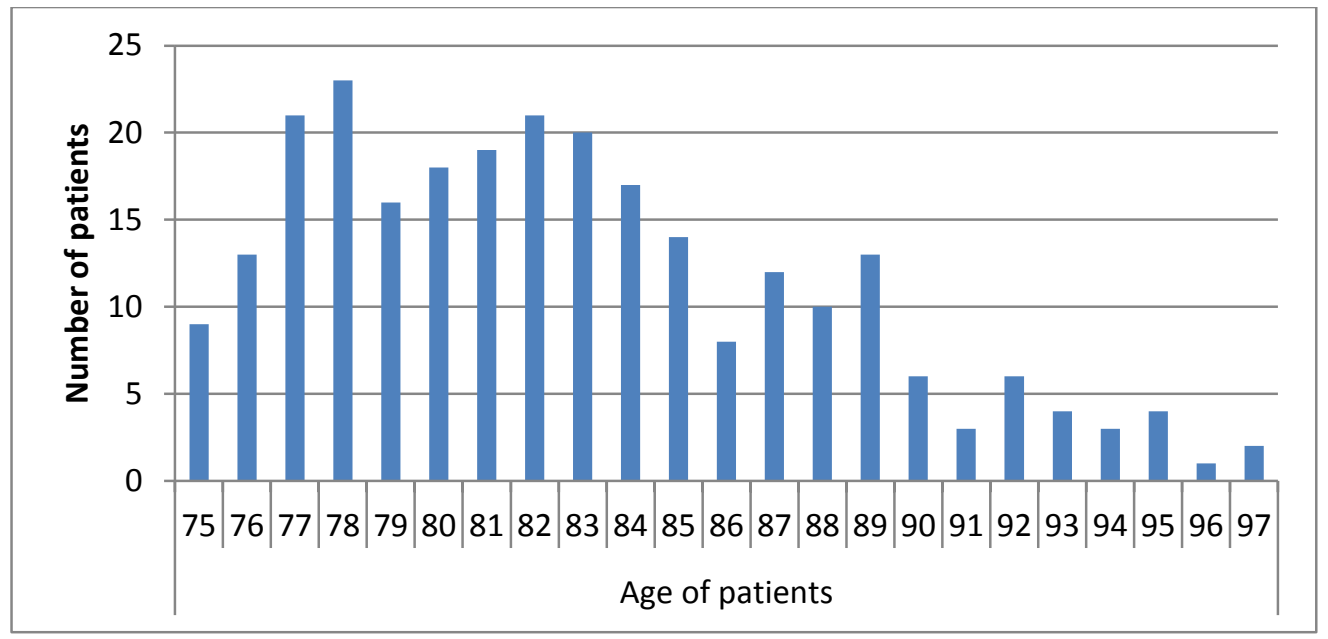

Figure 1. Distribution of ages of all patients aged 75 and over with head injuries admitted to the Southwest Neurosurgery Unit from 2007 - 2010.

\section{Diagnostic Categories}

Patients were divided into eight categories, based upon the predominant aspect on initial imaging (usually computerised tomography [CT]). 26 patients were admitted with acute subdural haematoma; 175 with chronic subdural haematoma; and 46 with mixed subdural collections, or acute-on-chronic subdural haematomas. Six patients predominantly had contusional brain injury, two skull fractures, four traumatic subarachnoid bleeds, two extradural haematomas and two foreign objects breaching the cranial vault.

\section{Subdural haematomas}

Subdural haematoma was by far the most common diagnosis of all the head injuries. Table 1 summarises the clinical characteristics of those with subdural haematomas, divided by the findings on imaging, or diagnosis as documented in the notes, where imaging could not be seen. Those presenting with acute subdural haematomas were more likely to be left-sided ( $p=0.005$ ), but were not more likely to be on an anticoagulant or antiplatelet medication $(p=0.212)$. 
Table 1. Characteristics of those admitted with subdural haematoma

\begin{tabular}{|c|c|c|c|c|}
\hline Characteristics & $\begin{array}{c}\text { Acute } \\
\text { subdurals }\end{array}$ & $\begin{array}{l}\text { Chronic } \\
\text { subdurals }\end{array}$ & $\begin{array}{c}\text { Mixed } \\
\text { subdurals }\end{array}$ & $\begin{array}{c}\text { All } \\
\text { subdurals }\end{array}$ \\
\hline Number & 26 & 175 & 46 & 247 \\
\hline Age & $80(75-94)$ & $83(75-97)$ & $82(76-95)$ & $82(75-97)$ \\
\hline Left-sided (\%) & 53.8 & 39.4 & 28.3 & 38.9 \\
\hline Mean maximal depth $(\mathrm{cm})$ & 1.2 & 2.5 * & 4.5 & $2.3 \dagger$ \\
\hline Depth range $(\mathrm{cm})$ & $0.5-2.3$ & $1.1-3.6$ * & $2.2-4.7$ & $0.5-4.7 \dagger$ \\
\hline Mean midline shift $(\mathrm{cm})$ & 0.7 & $1.1^{*}$ & 0.4 & $1.1 \dagger$ \\
\hline Right-sided (\%) & 42.3 & 41.7 & 32.6 & 40.1 \\
\hline Mean maximal depth $(\mathrm{cm})$ & $1.6 \ddagger$ & $2.4 \S$ & 1.9 & $2.2 \|$ \\
\hline Depth range $(\mathrm{cm})$ & $0.5-4.3 \ddagger$ & $0.7-3.6 \S$ & $0.8-3.6$ & $0.5-4.3 \|$ \\
\hline Mean midline shift $(\mathrm{cm})$ & $1.0 \ddagger$ & $1.0 \S$ & 0.9 & $1.0 \|$ \\
\hline Bilateral (\%) & 3.8 & 18.9 & 39.1 & 21.1 \\
\hline Mean maximal depth $(\mathrm{cm})$ & 2.0 & 4.0 ๆ & 4.4 & $4.2 \#$ \\
\hline Depth range $(\mathrm{cm})$ & $2.0-2.0$ & $2.1-6.49$ & $2.2-6.5$ & $2.0-6.5 \#$ \\
\hline Mean midline shift $(\mathrm{cm})$ & 0 & $0.3 \rrbracket$ & 1.3 & $0.4 \#$ \\
\hline Admission GCS & $13(6-15)$ & $14(6-15)$ & $14(3-15)$ & $14(3-15)$ \\
\hline ASA on admission & 3 & 3 & 3 & 3 \\
\hline Current smoker (\% of patients) & 0 & 5.1 & 2.1 & 4.0 \\
\hline Anticoagulation (\% of patients) & 69.2 & 54.3 & 47.8 & 54.7 \\
\hline$\%$ Aspirin & 19.2 & 27.4 & 17.4 & 24.7 \\
\hline$\%$ Clopidogrel & 0 & 1.1 & 2.2 & 1.2 \\
\hline$\%$ Clexane & 0 & 0.6 & 0 & 0.4 \\
\hline$\%$ Warfarin & 34.6 & 17.7 & 21.7 & 20.2 \\
\hline$\%$ Clopidogrel and aspirin & 11.5 & 1.7 & 2.2 & 2.8 \\
\hline \% Dipyridamole and aspirin & 0 & 5.1 & 2.2 & 4.0 \\
\hline$\%$ Warfarin and aspirin & 3.8 & 0.6 & 2.2 & 1.2 \\
\hline Mean INR (range) & $3.1(1-10)$ & $\begin{array}{c}2.7(1.1- \\
4.9) \\
\end{array}$ & $3.0(1-10)$ & $2.9(1-10)$ \\
\hline \multicolumn{5}{|l|}{ Main presenting complaint (\%) } \\
\hline Hemiparesis & 23.1 & 43.4 & 28.3 & 38.5 \\
\hline Confusion & 15.4 & 28.6 & 30.4 & 27.5 \\
\hline Unsteadiness & 0 & 10.9 & 6.5 & 8.9 \\
\hline Collapse & 19.2 & 1.7 & 8.7 & 4.9 \\
\hline Fall & 23.1 & 2.3 & 2.2 & 4.5 \\
\hline Dysphasia & 0 & 4.0 & 8.7 & 4.5 \\
\hline Decreased consciousness & 11.5 & 2.3 & 4.3 & 3.6 \\
\hline Headaches & 0 & 4.6 & 2.2 & 3.6 \\
\hline Seizure & 7.7 & 1.7 & 4.3 & 2.8 \\
\hline Dysarthria & 0 & 0 & 2.2 & 0.4 \\
\hline Facial weakness & 0 & 0.6 & 0 & 0.4 \\
\hline Dizziness & 0 & 0 & 2.2 & 0.4 \\
\hline
\end{tabular}

Unless otherwise stated, numbers are expressed as median (range). ${ }^{*}=$ of 68 patients for whom scans could be seen. $\dagger=$ of 95 patients for whom scans could be seen. $\ddagger=$ of 10 patients for whom scans could be seen. $\S=$ of 69 patients for whom scans could be seen. $\|=$ of 94 patients for whom scans could be seen. $\boldsymbol{\uparrow}=$ of 31 patients for whom scans could be seen. $\#=$ of 50 patients for whom scans could be seen. 
Table 2: Outcomes of those who were admitted with subdural haematoma

\begin{tabular}{|c|c|c|c|c|}
\hline Outcome & $\begin{array}{l}\text { Acute } \\
\text { subdurals }\end{array}$ & $\begin{array}{l}\text { Chronic } \\
\text { subdurals }\end{array}$ & $\begin{array}{l}\text { Mixed } \\
\text { subdurals }\end{array}$ & $\begin{array}{l}\text { All } \\
\text { subdurals }\end{array}$ \\
\hline $\begin{array}{l}\text { Length of neurosurgical } \\
\text { stay (days) }\end{array}$ & $8(1-30)$ & $6(1-49)$ & $6.5(1-31)$ & $6(1-49)$ \\
\hline$\%$ operated & 57.7 & 96 & 95.7 & 91.9 \\
\hline Operation & & & & \\
\hline$\%$ craniotomy & 80.0 & 2.4 & 22.7 & 11.5 \\
\hline$\%$ burrholes & 20.0 & 95.8 & 72.7 & 86.3 \\
\hline$\%$ minicraniotomy & 0 & 1.8 & 4.5 & 2.2 \\
\hline $\begin{array}{l}\text { Mean length of anaesthetic } \\
(\mathrm{h}: \mathrm{mm})\end{array}$ & 2:01 & $1: 26$ & $2: 04$ & $1: 36$ \\
\hline $\begin{array}{l}\text { Days from admission to } \\
\text { operation }\end{array}$ & $0(0-13)$ & $1(0-38)$ & $0(0-10)$ & $0(0-38)$ \\
\hline Discharge GCS & $14(3-15)$ & $15(3-15)$ & $15(3-15)$ & $15(3-15)$ \\
\hline$\%$ poor outcome & 57.9 & 17.7 & 34.8 & 25.1 \\
\hline $\begin{array}{l}\% \text { patients that had at least } \\
1 \text { complication* }\end{array}$ & 46.1 & 24.0 & 41.3 & 28.7 \\
\hline $\begin{array}{l}\text { \% infection, inc UTI, chest } \\
\text { infection, cellulitis) }\end{array}$ & 19.2 & 2.3 & 15.2 & 6.5 \\
\hline $\begin{array}{l}\% \text { cardiac complication (inc } \\
\text { AF, NSTEMI, LVF) }\end{array}$ & 0 & 1.7 & 4.3 & 2.0 \\
\hline$\%$ new neurological deficit & 0 & 0.6 & 2.2 & 0.8 \\
\hline$\%$ seizures & 15.4 & 2.9 & 4.3 & 4.5 \\
\hline$\%$ operative wound infection & 0 & 1.1 & 0 & 0.8 \\
\hline$\%$ subdural reaccumulation & 11.5 & 16.0 & 6.5 & 13.7 \\
\hline $\begin{array}{l}\text { \% operation after non- } \\
\text { operative decision }\end{array}$ & 3.8 & 1.1 & 2.2 & 0.8 \\
\hline$\%$ tracheostomy insertion & 3.8 & 0 & 2.2 & 0.8 \\
\hline$\%$ cerebral infarction & 3.8 & 0.6 & 2.2 & 1.2 \\
\hline$\%$ hypoxic brain injury & 0 & 0 & 0 & 0.4 \\
\hline$\%$ cerebral oedema & 3.8 & 0 & 0 & 0.4 \\
\hline $\begin{array}{l}\% \text { other (eg gastritis, urinary } \\
\text { retention, paralytic ileus) }\end{array}$ & 0 & 1.7 & 2.2 & 1.6 \\
\hline $\begin{array}{l}\text { Number of post-op } \\
\text { pneumocephalus/number } \\
\text { underwent post op scan }\end{array}$ & $1 / 9$ & $27 / 73$ & $14 / 22$ & $42 / 104$ \\
\hline $\begin{array}{l}\text { Mean \% decrease in } \\
\text { subdural depth after } \\
\text { operation }\end{array}$ & 23.4 & 26.4 & 20.7 & 24.9 \\
\hline$\%$ required further operation & 7.7 & 17.7 & 8.7 & 15.4 \\
\hline$\%$ required ITU & 50 & 5.1 & 15.2 & 11.7 \\
\hline$\%$ readmitted & 3.8 & 14.3 & 8.7 & 12.1 \\
\hline $\begin{array}{l}\text { Number of days to } \\
\text { readmission }\end{array}$ & $4(4-4)$ & $17(4-130)$ & $17.5(1-78)$ & $\begin{array}{c}15.5(1- \\
130)\end{array}$ \\
\hline$\%$ Died & & & & \\
\hline$\%$ As inpatient & 38.5 & 4.0 & 4.3 & 7.7 \\
\hline$\%$ Within $14 \mathrm{~d}$ of discharge & 3.8 & 0.6 & 0 & 0.8 \\
\hline$\% 14-30 d$ post-discharge & 3.8 & 1.7 & 2.2 & 2.0 \\
\hline
\end{tabular}




\begin{tabular}{|l|c|c|c|c|}
\hline $\begin{array}{c}\text { \% Within 1 - 6 months of } \\
\text { discharge }\end{array}$ & 11.5 & 19.6 & 10.3 & 12.1 \\
$\begin{array}{c}\% \text { 6 months to 1 year after } \\
\text { discharge }\end{array}$ & 0 & 0 & 3.4 & 2.4 \\
$\begin{array}{c}\% \text { Between 1 year post } \\
\text { discharge and 31/12/2012 }\end{array}$ & 11.5 & 15.4 & 13.0 & 14.6 \\
\hline
\end{tabular}

Unless otherwise stated, numbers are expressed as median (range). ${ }^{*}=\mathrm{NB}$. some patients had more than one complication, and so may be counted twice in the complication section

\section{Death}

No patient with ASDH over 90 years old survived admission ( $\mathrm{N}=3)$. Of eight patients with ASDH that were admitted with a GCS under 10, only one survived. However, patients with CSDHs and mixed-density subdurals, with presenting GCS as low as 3 , survived. Those with acute subdural haematomas had a significantly lower survival rate $(p<0.001)$, as shown in the Kaplan-Meier curve in Figure 2 . The odds of inpatient death for patients with acute subdural haematomas was 15.38 times higher (95\% Cl 1.53 - 166.67, $\mathrm{p}=0.02$ ) than those with chronic subdurals, and 16.39 higher $(95 \% \mathrm{Cl} 1.24-200, \mathrm{p}=0.034)$ than those with mixed subdural haematomas.

For all subdural haematomas, low ASA (score 4 or 5 , vs 1 to 3 ) predicted death as an inpatient (OR $10.44,95 \% \mathrm{Cl} 2.00-54.60 ; \mathrm{p}=0.005)$, and was the only predictor of death by 30 days (OR $7.68,95 \% \mathrm{Cl} 1.76-33.49, \mathrm{p}=0.007)$.

Death by one year was predicted by moderate/severe admission GCS (when compared with mild GCS [OR 3.80, 95\% $\mathrm{Cl} 1.15$ - 12.8; $\mathrm{p}=0.028$ ]), longer duration of anaesthetic $(p=0.002)$, and having bilateral subdural haematomas (as opposed to unilateral, OR 13.26, 95\% Cl 2.67 - 66.0; $p=0.002)$. 


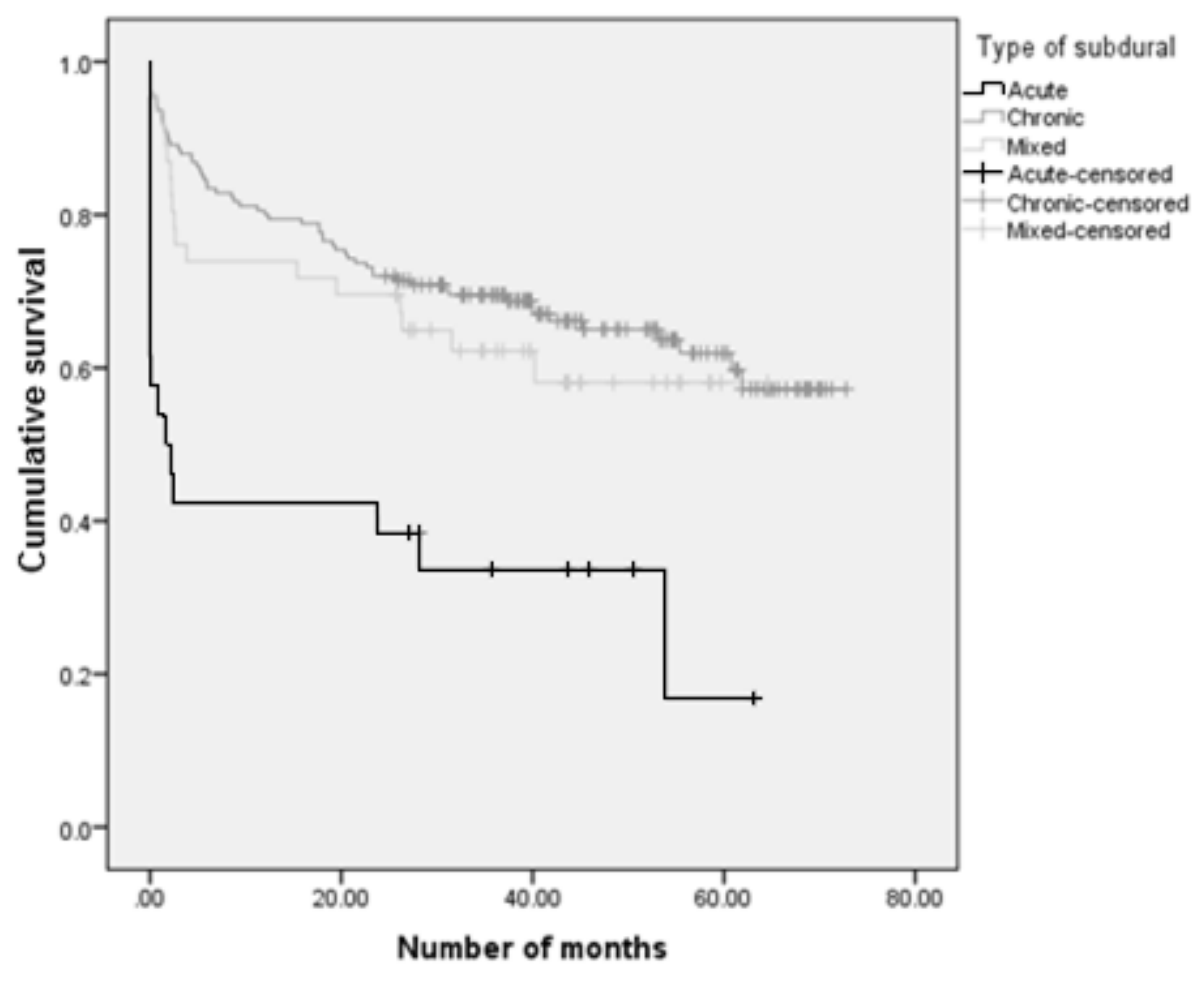

Figure 2. A Kaplan-Meier survival curve to show the deaths of patients with acute, chronic and mixed subdural haematomas.

Of those patients with acute subdural haematoma that had died, eight had documented causes of death within their notes. All these deaths were attributable to their subdural haemorrhage, although for one the primary cause was bronchopneumonia, with subdural haematoma secondary. One patient that died did not undergo active intervention after discussion with relatives, who felt it would not be in the best interests of the patient.

For the mixed-density subdurals, four had documented causes of death. As inpatients, two had bronchopneumonia related to subdural haematoma; one died of hypoxic brain injury. 79 days after discharge one patient died of bronchopneumonia secondary to CVE.

Eight patients with chronic subdural haematomas died in hospital. Three died of complicating pneumonia (one of which was due to MRSA), one died of coronary artery thrombosis, one sepsis, one of mitral regurgitation, one breast cancer, and one cerebral infarction.

Poor discharge outcome 
Unsatisfactory GOS ( 1 to 3 ) was predicted by age over 85 (for ages 85 - 89 OR 3.63 , $95 \% \mathrm{Cl} 1.14-11.57, \mathrm{p}=0.029$ ), and more so by age over 90 (OR 10.49, 95\% $\mathrm{Cl} 2.72$ - 40.37; $p=0.001$ ). It was also significantly associated with larger depth of subdural $(p<0.001)$ and the occurrence of a complication (OR 3.24, 95\% Cl 1.49 - 7.04; $\mathrm{p}=0.003)$.

\section{Other outcomes}

Recurrence was significantly predicted only by bilateral site of subdural haematoma (OR $4.59,95 \% \mathrm{Cl} 1.36-15.54 ; \mathrm{p}=0.014$ ). This also was the only variable to predict reoperation (OR 4.38, 95\% Cl $1.44-13.37 ; p=0.009$ ). No variables were found to predict readmission to the neurosurgical unit.

There were significantly more complications for those patients that underwent craniotomy or minicraniotomy, compared to burrholes (OR 4.02, 95\% Cl 1.64 - 9.84; $\mathrm{p}=0.002$ ).

\section{Other diagnoses}

Four patients were admitted with predominantly traumatic subarachnoid haemorrhage. Two were GCS 15 on admission, and one GCS 12, all had "satisfactory" outcome, based upon GOS. One was GCS 3 on admission, after a seizure, and died of a myocardial infarction. None required operation.

Six patients were admitted that primarily had contusional injury. Three were GCS 15 on admission and discharge, all with satisfactory outcomes. One patient was GCS 9 on admission, and died nine days later. None underwent operation.

Two patients were admitted with extradural haematomas. One had a maximum axial depth of $0.6 \mathrm{~cm}$, the other $2.0 \mathrm{cms}$. Admission GCS were 13 and 14 , respectively. The $2 \mathrm{~cm}$ extradural haematoma was evacuated on the day of admission. Both patients had a satisfactory discharge outcome, and died two and three years after discharge, respectively.

Two patients were admitted with a piercing foreign object in their cranium. One was due to falling on the foot piece of their wheelchair, which became embedded in the skull. They were GCS 14 on admission, underwent removal on the day of admission, but died four days later. The other patient had a garage door fall on their head, and 
was GCS 10 on admission and discharge, with a poor outcome (GOS 3). This patient was also operated upon on the day of admission.

Two patients were admitted with skull fractures, one to the frontal sinus and one occipital. Both were GCS 15 on admission and discharge, with satisfactory discharge GOS. Neither required operation, but were observed for eighteen and nine days, respectively.

\section{Discussion}

This study identified 263 patients, aged 75 years and over, that were admitted to a regional neurosurgery unit with head injury, over a period of four years. As may be expected by those in the field, the majority had sustained subdural haematomas, with 175 at a chronic stage, 26 acutely presenting, and 46 appearing acute-onchronic. Other diagnoses consisted of 6 predominantly contusional injury, 2 fractures, 4 traumatic subarachnoid haemorrhages, 2 extradural haemorrhages, and 2 piercing foreign bodies.

In the past, there has been some reluctance about treating elderly patients with head trauma. Maurice-Williams extols the virtues of treating elderly patients that are otherwise fit, except in emergency surgery ${ }^{7}$, especially head injury ${ }^{8}$. Mohindra et al from India (2008) found that the elderly do poorly after severe head injuries and have a $66 \%$ mortality rate, whereas in younger patients, mortality is only $28 \%{ }^{9}$ Munro et al (2002) found that rates of survival and transfer to specialist neurosurgical care were significantly lower for those aged 65 and over with acute, traumatic intracranial haematomas, independent of extracranial injuries, measures of physiological status and haematoma size. ${ }^{10}$ The elderly were also less likely to have CT scan within 6 hours of arrival in the emergency department. However, $77 \%$ of the elderly that underwent neurosurgery survived, with a longer duration of admission than the younger cohort. They commented that "It is possible... that doctors' concerns over functional outcomes and survival rates in past studies may have produced a degree of scepticism over the worth of treating older patients with head injuries." 
The patients in our cohort seem to fare better, with the inpatient mortality rate for subdural haematomas at only $7.7 \%$, and a $25 \%$ mortality rate by one year. Threequarters of patients had a good outcome at discharge. Those with acute subdural haematomas had significantly worse outcome in terms of death, with $57.6 \%$ dead by one year, $38.5 \%$ of which died as inpatients. Only $42.1 \%$ had a good outcome at discharge.

Perhaps, those at the extremes of age, or that have a lower admission GCS, are more likely to have a poor outcome? ${ }^{11}$ Ritchie et al (2000) found that there were no satisfactory outcomes for head injury patients over the age of 80 with an initial GCS under 13 , however, this was not reflected in our data, where $13 / 27$ of subdural haematoma patients with a presenting GCS under 13 had a good outcome. However, only one of five patients aged over 89 with a presenting GCS under 13 had a good outcome at discharge, two dying as inpatients. Ritchie also found that all those with an initial GCS under 11 were either dead, vegetative or required full nursing care upon discharge, but 16 of 34 subdural haematoma patients that met this criterion in our series had a "good" GOS.

However, all patients with ASDH aged over 90 died during admission, and only 1 of 10 over the age of 90 with a presentation GCS under 10, survived, with an outcome of moderate disability.

In fact, for all subdurals, the only predictor of early death, as an inpatient or by 30 days, was ASA grade. GCS did not predict this, although in the longer term, a moderate/severe head injury as determined by GCS did predict death within one year, as did longer anaesthetic time and the presence of bilateral haematomas.

For those for whom death certification was available, we found that those with acute subdurals died from their injury, however those who died after chronic subdural haematomas died of other medical conditions. Perhaps this is because their injury, which seems relatively well-tolerated otherwise, and the consequent stay in hospital, are insults that push the physiologically vulnerable too far. 
There were small numbers of patients admitted with other traumatic head injuries, and generally, those with a GCS of 10 or under had a poor outcome, with three of four dying as an inpatient.

For those with subdural haematoma, the only outcome that was predicted by advanced age, over 85 years old, was poor GOS at discharge. This was also associated with larger subdural haematomas, possibly due to compression of the underlying brain resulting in neurological deficits; and the occurrence of a complication, with the potential extra issues or disabilities they may incur, independent of the presenting diagnosis.

Recurrence and need for reoperation were predicted by bilateral location of subdural haematomas, identifying a group that particularly may require more precision and thoroughness during their original operation and post-operative care to avoid these.

In Ritchie's series, there was a 5.4\% complication rate, and $9.8 \%$ recurrence. Our complication rate in patients with subdural haematoma was higher, at $15.7 \%$, excluding the $13.7 \%$ reaccumulation rate. It may be that this rate is higher due to a lower threshold of inclusion, for example urinary tract infections and seizures were included in our data collection.

Mori and Maeda (2001) found that most of their patients with subdural haematomas presented with gait disturbance (63\%) and hemiparesis (58.6\%). Hemiparesis was the most common main presentation within our cohort (38.5\%), followed by confusion (27.5\%) and unsteadiness (8.9\%). ${ }^{12}$ We found that patients with acute subdural haematomas were more likely to have left-sided haematomas. This may be because the left side is the more eloquent side in the majority of people, and thus a similar degree of compression on this side of the brain may result in more symptoms in the acute phase.

Anticoagulation has also been a deterring factor, when considering treatment of the elderly. Coagulopathy was more likely to confer poor outcome in Mori's series (2001), ${ }^{12}$ and although $69.2 \%$ of subdural haematoma patients were on some form of anticoagulant or antiplatelet medication, this did not seem to lead to any negative 
outcomes. Karni et al found that $5.8 \%$ of patients over the age of 65 years that presented with intracranial haematoma due to trauma, had raised INR due to warfarin therapy. There was a $50 \% 30$-day mortality rate. ${ }^{13} 21.4 \%$ of our patients with subdural haematoma were on warfarin at admission, with only $13.2 \%$ of those dying within 30 days. These improved figures may have been related to the approach we take with those patients on anticoagulant and antiplatelet medication. All those on warfarin that are operated upon in an emergency situation have their anticoagulant state reversed using vitamin $\mathrm{K}$ and prothrombin complex concentrate, and all those on antiplatelet medication (for example, aspirin or clopidogrel) receive a unit of platelets at anaesthetic induction. For patients on antiplatelet medications with chronic subdural haematomas that have only minor, subtle symptoms, we postpone operating for 5 - 7 days until the antiplatelet effects have worn off, operating in a more urgent fashion if the patient's symptoms progress, with platelet cover at anaesthetic induction.

The main limitation of this study is that it concerns only those patients that were admitted to our neurosurgical unit, not all those that were referred. There is therefore an inherent selection bias, those patients that are considered too unwell, or even too old, by the consultant on-call, are not included here. This means that the above results apply to those patients that are thought to be well enough to benefit from neurosurgical management. The retrospective nature means that unfortunately not all scans could be seen and diagnoses verified.

\section{Conclusion}

As stated by Chibbaro et al (2011), it is likely that there has been a slow evolution in the experience and attitudes of many neurosurgeons, to increasingly consider active, operative management in the treatment of the elderly with head injuries. ${ }^{14}$ The elderly population is extremely diverse, in terms of health, with some surviving into their eighties, independent, with few co-morbidities. Neurosurgeons are seeing increasing proportions of patients referred and treated in their units. ${ }^{6,7}$ We found no particular age cut-off above which all patients that require admission to a neurosurgical unit do poorly, except for the small number of those aged over 90 with ASDH, all of which died. Generally, all patients with ASDH performed quite poorly. All patients over 90 years old with a GCS under 10 had poor outcomes, and so there should be significant consideration about the benefits of treating these groups of 
patients. Bilateral subdural haematomas are more likely to recur and require operation, and so special care and attention should be undertaken in managing these patients.

\section{Highlights}

- Most patients are admitted with subdural haematoma, especially chronic haematoma

- Inpatient mortality rate was $7.7 \%$, one year mortality rate was $25 \%$

- Those with acute subdural haematomas had a significantly lower survival rate

- Only 1 of 8 patients with acute subdural haematoma and GCS <10 survived

- Poor outcome was predicted by age over 85 , but death and complications were not

\section{References}

1 United Nations. World population prospects. Available at:

http://www.un.org/esa/population/publications/wpp2000/chapter5.pdf. Accessed 22.03.15.

2 Cornwell J. Continuity of care for older hospital patients: A call for action. London: King's Fund, 2012.

3 Pentland B, Jones PA, Roy CW, Miller J. Head injury in the elderly. Age and Ageing 1986;15:193-202.

4 Howard MA, Gross AS, Dacey RG, Winn HR. Acute subdural haematomas: an age-dependent clinical entity. J Neurosurg 1989;71:858-63.

5 Ritchie PD, Cameron PA, Ugoni AM, Kaye, AH. A study of the functional outcome and mortality in elderly patients with head injuries. Journal of Clinical Neuroscience 2000;7(4):301-304.

6 Whitehouse KJ, Jeyaretna DS, Wright, A, Whitfield PC. Neurosurgical Care in the Elderly: Increasing demands necessitate future healthcare planning. World Neurosurgery 2016;87:446-454.

7 Maurice-Williams RS, Kitchen N. The scope of neurosurgery for elderly people. Age and Ageing 1993;22:337-342. 
8 Maurice-Williams RS. Neurosurgery in the elderly. British Journal of Neurosurgery 1994;8:651-653

9 Mohindra S, Mukherjee KK, Gupta R, Chhabra R. Continuation of poor surgical outcome after elderly brain injury. Surgical neurology 2008;69:474-477.

10 Munro PT, Smith RD, Parke TRJ. Effect of patients' age on management of acute intracranial haematoma:prospective national study. BMJ 2002;325:1001-1005. 11 Ritchie PD, Cameron PA, Ugoni AM, Kaye, AH. A study of the functional outcome and mortality in elderly patients with head injuries Journal of Clinical Neuroscience 2000;7(4):301-304.

12 Mori K, Maeda, M. Surgical treatment of chronic subdural hematoma in 500 consecutive cases: clinical characteristics, surgical outcome, complications and recurrence rate. Neurol Med Chir (Tokyo) 2001;41:371-381.

13 Karni A, Holtzman R, Bass T, Zorman,G, Carter L, Rodriguez L, Bennettshipman VJ, Lottenburg L. Traumatic Head Injury in the anticoagulated patient: A lethal combination. The American Surgeon. 2001;67:1098-1100.

14 Chibbaro S, Di Rocco F, Makiese O, Mirone G, Marsella M, Lukaszewicz AC, Vicaut E, Turner B, Hamdi S, Spiriev T, Di Emidio P, Pirracchio R, Payen D, George B, Bresson D. Neurosurgery and elderly: analysis through the years. Neurosurg Rev 2011;34:229-234. 